\title{
VARIABILIDADE ESPACIAL DA EFICIÊNCIA DO USO DE POTÁSSIO E FÓSFORO NA CULTURA DA SOJA ${ }^{1}$
}

Rafael Noetzold² ${ }^{\text {, Marcelo de Carvalho Alves }}$, Marcio Marcos Goussain Júnior ${ }^{4}$ \& Rita de Cássia Santos Goussain ${ }^{5}$

1 - Parte da tese de doutorado do primeiro autor

2 - Prof. Dr. da UNEMAT, Nova Mutum-MT, rafael_noetzold@hotmail.com

3 - Prof. Dr. da UFLA, Lavras-MG, marcelo.alves@ufla.br

4 - Dr. da Assist Consultoria e Experimentação Agronômica, Campo Verde-MT, marcio.goussain@assistconsult.com.br

5 - Profa. Dra. do Instituto Federal de Educação, Ciência e Tecnologia de Mato Grosso, Santo Antonio do Leverger-MT, rita.cassia@svc.ifmt.edu.br

\section{Palavras-chave:}

argila

Glycine max

macronutrientes

produtividade

sojicultura de precisão

\section{RESUMO}

$\mathrm{Na}$ agricultura de precisão, o tratamento diferenciado, dentro de uma mesma área, contribui para a racionalização dos insumos agrícolas. Objetivou-se nesta pesquisa avaliar a dependência espacial e o mapeamento da eficiência de cloreto de potássio e superfosfato simples em áreas de cultivo de soja. Coletaram-se amostras de solo em pontos georreferenciados em quatro talhões pertencentes ao município de Campo Verde-MT. Em seguida, foram determinados os atributos químicos do solo e sua textura, para posteriormente efetuar recomendação de adubação em taxa para produzir 50 sacas/ha de grãos de soja. Após a coleta de plantas nos mesmos locais georreferenciados para solo, obteve-se a produtividade de grãos de soja. Posteriormente, calculou-se a eficiência do uso de cloreto de potássio e superfosfato simples, e em seguida foram realizadas análises descritiva e geoestatística para todos os atributos estudados. Os níveis de $\mathrm{pH}$, teores de argila, matéria orgânica, potássio, fósforo, a produtividade de grãos e a eficiência do uso de cloreto de potássio e superfosfato simples apresentaram variabilidade, com distribuições espaciais definidas nos quatro talhões. Ocorreu dependência espacial e foi possível mapear a eficiência do uso de superfosfato simples e cloreto de potássio na cultura da soja. $\mathrm{O}$ teor de matéria orgânica do solo influenciou positivamente na eficiência de cloreto de potássio. Áreas com menor variabilidade espacial dos atributos do solo resultam em maior produtividade de grãos de soja e maior eficiência de superfosfato simples e cloreto de potássio.

\section{Keywords:}

clay

Glycine max

macronutrients

yield

precision soybean production

\section{SPATIAL VARIABILITY OF POTASSIUM AND PHOSPHORUS EFFICIENCY USE IN} SOYBEAN CROP

\section{ABSTRACT}

In precision agriculture, the differential treatment, within the same area, contributes to agricultural input rationalization. The aim of this research was to evaluate the spatial dependence and mapping superphosphate and potassium chloride efficiency in soybean growing areas. Soil samples were collected at georeferenced points in four plots belonging to the municipality of Campo Verde-Mato Grosso. Then soil chemical properties and texture were determined to further perform descriptive analysis, geostatistics of these attributes and fertilizer recommendation in charge to produce 3000 $\mathrm{kg} \mathrm{ha}^{-1}$ of soybeans. After collecting plants in the same locations for georeferenced soil, soybean grain yield was obtained, and the superphosphate and potassium chloride use efficiency were calculated, having geostatistical analysis also been held. The $\mathrm{pH}$, clay, organic matter, potassium, phosphorus contents and yield, superphosphate and potassium chloride efficiency use showed variability with spatial patterns defined in the four areas. Spatial dependence was found and it was possible to map the superphosphate and potassium chloride use efficiency in soybeans. The organic matter content of the soil had a positive influence on the potassium chloride efficiency. Areas with lower spatial variability of soil attributes result in higher soybean yield and higher efficiency of superphosphate and potassium chloride. 


\section{INTRODUÇÃO}

O Estado de Mato Grosso é o maior produtor de soja do Brasil. Estima-se que foram colhidas, na safra 2018/2019, 32.306,1 mil toneladas (CONAB, 2019), cultivadas principalmente no bioma Cerrado.

Conforme Melo \& Alleoni (2009), a baixa fertilidade dos solos do Cerrado é atribuída ao material de origem, aos processos de intemperismo e às práticas utilizadas pelo agricultor, resultando em baixa produtividade em determinadas áreas. Assim, é fundamental o uso de práticas de manejo com o intuito de aumentar a fertilidade e minimizar a variabilidade do solo, sendo que as ferramentas de agricultura de precisão estão sendo utilizadas com êxito.

Para Carvalho et al. (2018), o conhecimento da variabilidade espacial de atributos químicos do solo permite a aplicação de insumos de forma eficiente. Assim, as práticas de manejo precisas, utilizadas para locais específicos, empregadas nas decisões acerca do manejo dos fertilizantes, tornam possível conciliar os interesses dos investidores com os fatores agronômicos (REETZ JR., 2010). Dessa forma, essas práticas podem contribuir para diminuição da variabilidade espacial da fertilidade do solo e da produtividade das culturas, para redução e racionalização da quantidade de insumos aplicada e, consequentemente, aumento da lucratividade.

Para Dalchiavon et al. (2017), o conhecimento da espacialização dos atributos químicos do solo contribui para o estabelecimento de práticas sustentáveis de manejo do solo e das culturas; e, para Bottega et al. (2013), a interação entre os atributos do solo, do genótipo e as demais características do ambiente interfere no potencial produtivo das culturas e, na maioria das vezes, é possível verificar variabilidade da produtividade de grãos.

Dessa forma, o mapeamento da fertilidade do solo permite estabelecer zonas de manejo que podem ser tratadas de maneira específica (ZONTA et al., 2014), sendo que as informações contidas nesses mapas contribuem para tomadas de decisões. Destaca-se também que o mapeamento da eficiência do uso de fertilizantes contribui para o melhor entendimento das interações que ocorrem durante o ciclo da soja.

$O$ conhecimento da variabilidade espacial da eficiência do uso de fertilizantes é essencial para obter informações referentes à localização das áreas com menor e maior amplitude da aplicação de fertilizantes e da produtividade das culturas, visando à sustentabilidade do sistema produtivo. Nesse sentido, a hipótese deste trabalho foi de que ocorre dependência espacial da eficiência de fósforo e potássio na cultura da soja. Assim, objetivou-se avaliar a dependência espacial e o mapeamento da eficiência do uso de fósforo e potássio em áreas de cultivo de soja.

\section{MATERIAL E MÉTODOS}

A pesquisa foi realizada no município de Campo Verde, no sul de Mato Grosso. O clima na região é do tipo tropical quente e subúmido (Aw), segundo a classificação de Köppen. Conforme dados da Estação Meteorológica Vantage PRO2 Davis da Assist Consultoria e Experimentação Agronômica, instalada em Campo Verde, MT, a precipitação pluviométrica total foi de $1517,0 \mathrm{~mm}$, temperaturas diárias: mínima de $17,8{ }^{\circ} \mathrm{C}$; máxima de $35,7^{\circ} \mathrm{C}$ e média de $24,9^{\circ} \mathrm{C}$ entre e semeadura e a colheita da soja.

A coleta de dados dos atributos do solo e da produtividade de soja, safra 2012/2013, ocorreu em quatro áreas comerciais de produção de soja grão, nomeadas de talhões $1,2,3$ e 4, com áreas de 93,14 ha, 107,44 ha, 157,73 ha e 154,55 ha, respectivamente (Figura 1), ambos com o solo pertencente à classe dos Latossolos (SANTOS et al., 2013).

Essas áreas são manejadas mecanicamente no sistema de produção de sucessão soja-milho em três talhões. No talhão 2 , ocorre a rotação entre soja, milho e algodão, sendo que desde 2010 foi adotado o sistema de cultivo mínimo e a adubação em taxa variável para os quatro talhões.

Cada ponto foi representado por uma quadrícula de aproximadamente quatro hectares, sendo coletados 22, 24, 39 e 43 pontos, respectivamente, para os talhões 1, 2, 3 e 4 (Figura 1). Em cada um dos pontos, por meio de caminhamento em ziguezague, foi retirada uma amostra composta por cinco 

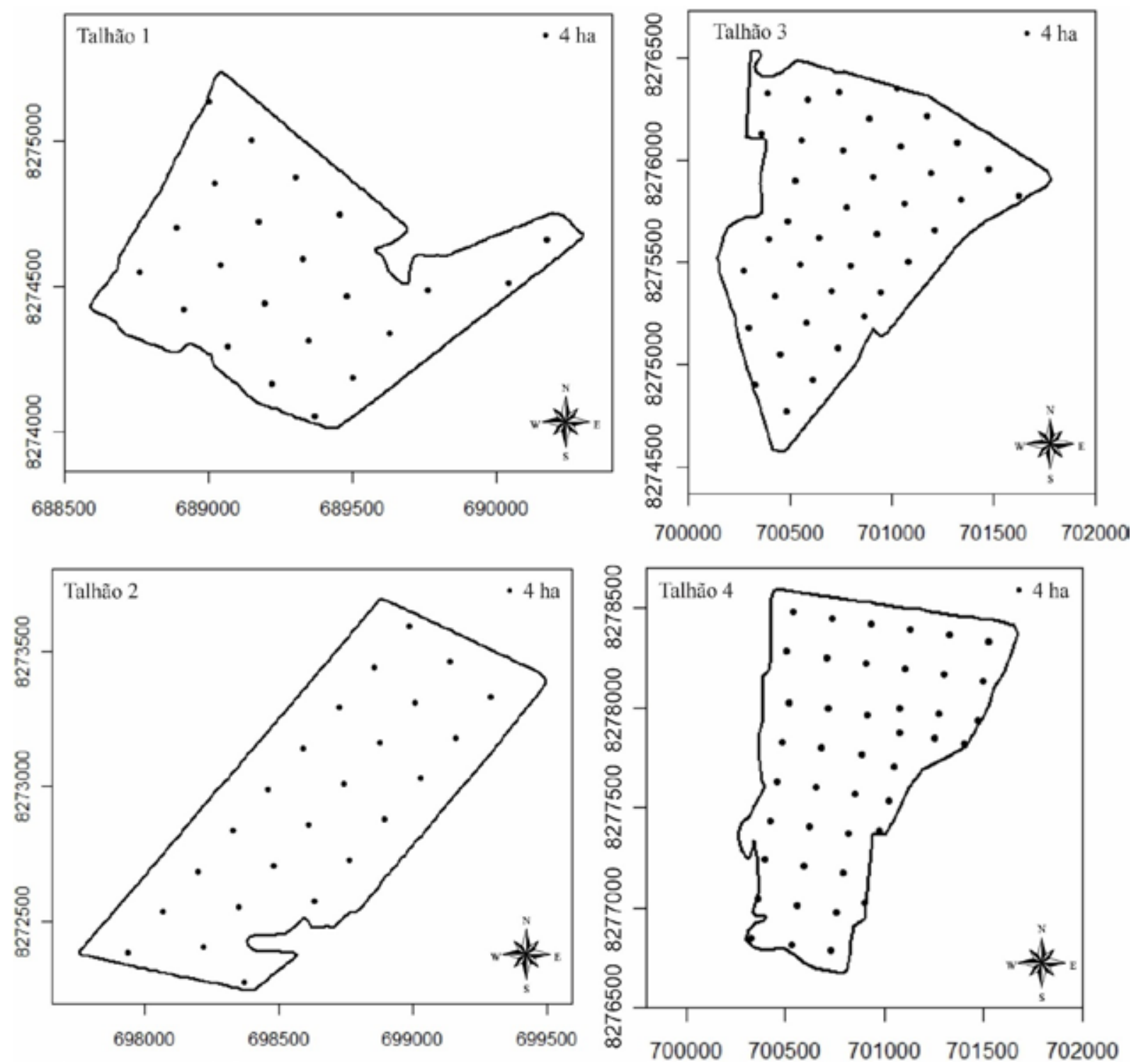

Figura 1. Malhas amostrais da coleta de solo nos talhões 1 a 4 na profundidade de $0,0-0,20 \mathrm{~m}$.

subamostras, sendo cada subamostra composta por duas repetições e o par de coordenadas usadas nas análises geoestatísticas foi o ponto central de cada quadrícula (Figura 2), as quais foram obtidas por GPS Mio P 350 configurado em datum WGS $84 \mathrm{e}$ fuso 21, acoplado ao guidão de uma motocicleta. A coleta do solo foi realizada nas entrelinhas das culturas agrícolas anteriores (algodão no talhão $2 \mathrm{e}$ milho nos demais talhões), na profundidade de 0,0 a $0,20 \mathrm{~m}$. Para isso, utilizou-se uma parafusadeira com broca de uma polegada de diâmetro, acoplada em uma motocicleta.

As amostras de solo coletadas foram encaminhadas ao laboratório para se efetuarem as seguintes análises: análise textural (areia, argila e silte), potencial hidrogeniônico $(\mathrm{pH})$, fósforo $(\mathrm{P})$, potássio $(\mathrm{K})$, cálcio $(\mathrm{Ca})$, magnésio $(\mathrm{Mg})$, alumínio $(\mathrm{Al})$, hidrogênio $(\mathrm{H})$, matéria orgânica $(\mathrm{MO})$, foi utilizada a extração por Mehlich I e os resultados foram apresentados em $\mathrm{mg} / \mathrm{dm}^{3}$. Foi empregada a extração por cloreto de potássio $0,1 \mathrm{M}$ para $\mathrm{Ca}, \mathrm{Mg}$ e $\mathrm{Al}\left(\mathrm{cmol}_{\mathrm{c}} / \mathrm{dm}^{3}\right)$ e a $\mathrm{MO}\left(\mathrm{mg} / \mathrm{dm}^{3}\right)$ foi obtida pela extração em dicromato de sódio $4 \mathrm{~N}^{2} \mathrm{H}_{2} \mathrm{SO}_{4} 10 \mathrm{~N}$. A leitura do $\mathrm{pH}$ foi efetuada em cloreto de cálcio $\left(\mathrm{CaCl}_{2}\right)$.

Com base na análise de fertilidade dos respectivos talhões, efetuou-se a recomendação em taxa variável de $\mathrm{K}$ e $\mathrm{P}$, conforme recomendações de adubação da Embrapa Soja (2011), visando produzir 50 sacas/ha. Para a recomendação de $\mathrm{P}$ em 


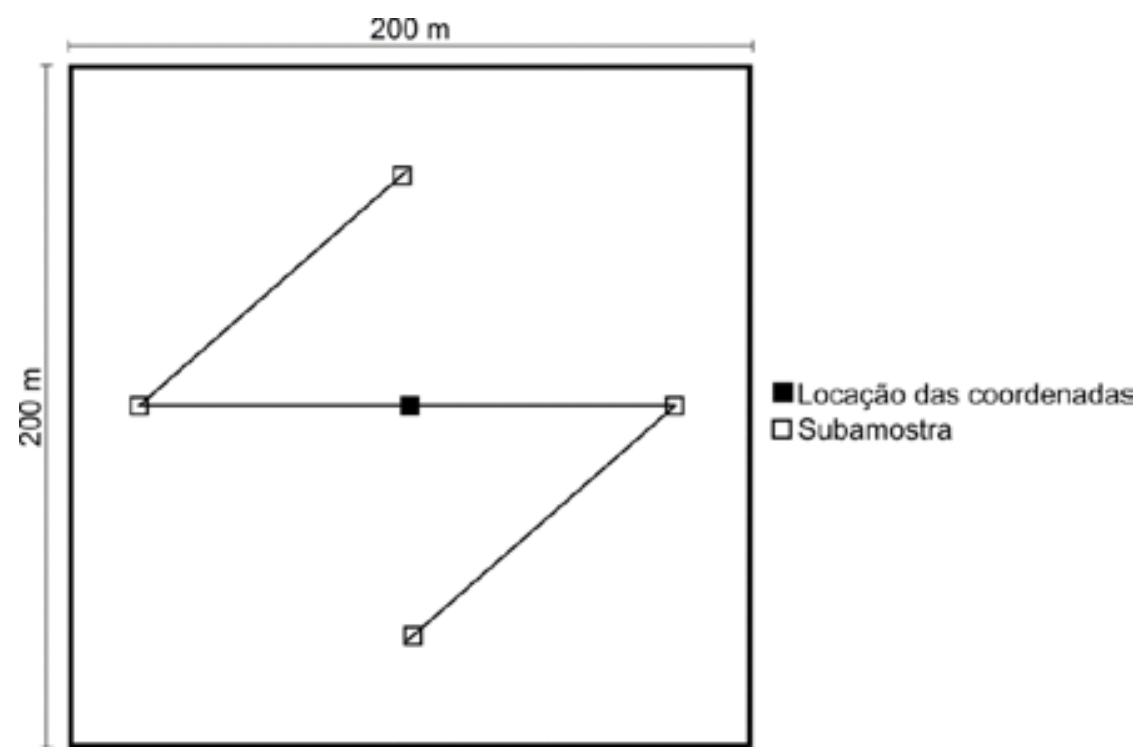

Figura 2. Esquema de amostragem de solo na profundidade de 0,0 a $0,20 \mathrm{~m}$ em cada ponto amostral.

taxa variável, foi considerado o teor desse nutriente presente no solo e a porcentagem da argila em cada ponto amostral. Com relação ao K, foi considerado o teor do nutriente no solo em cada ponto amostral e o aproveitamento pelas plantas. Foram utilizados $60 \mathrm{~kg}$ de $\mathrm{P}_{2} \mathrm{O}_{5} /$ ha (superfosfato simples) e $60 \mathrm{~kg}$ de $\mathrm{K}_{2} \mathrm{O} /$ ha (cloreto de potássio).

Para gerar os mapas de adubação em taxa variável, utilizou-se o critério de álgebra de mapas, em sistema de informação geográfica. As fontes de $\mathrm{P}$ e $\mathrm{K}$ foram aplicadas a lanço aos 30 e 20 dias antes da semeadura da soja, respectivamente. A aplicação em taxa variável de fertilizantes foi a lanço na superfície do solo, sem incorporação, com a utilização de um lancer Jam multiuso 12 ton, tracionado por um trator, com $140 \mathrm{CV}$, conforme as doses recomendadas.

A semeadura do cultivar 7639 RR foi realizada no mês outubro de 2012, com espaçamento de $0,45 \mathrm{~m}$ entre linhas. Os talhões foram submetidos à prática de manejo do cultivo mínimo, com semeadura sob a palhada de milho, nos talhões 1,3 e 4; e sob palhada de algodoeiro no talhão 2.

A coleta de plantas de soja (estádio R9), para a obtenção da produtividade de grãos em cada ponto georreferenciado (Figura 1), foi realizada nos meses de janeiro e fevereiro de 2013. Cada amostra foi composta por todas as plantas de soja contidas em duas linhas, com três metros de comprimento cada, correspondendo a $2,7 \mathrm{~m}^{2}$.

As plantas foram arrancadas manualmente, amarradas com identificação do ponto amostral e respectivo talhão e encaminhadas para dois barracões arejados, onde permaneceram até estarem secas. As amostras úmidas foram expostas ao sol.

Posteriormente, a trilha foi realizada com um batedor $\mathrm{SB}$, e as amostras foram acondicionadas em sacos de papel. Após a retirada das impurezas de cada amostra, utilizando-se peneira e ventilador, a produtividade final de grãos de soja foi obtida por meio da pesagem das amostras, com padronização do teor de água a $14 \%$.

Para estimar a eficiência de uso de superfosfato simples e cloreto de potássio e o efeito da dose de adubação sob a produtividade de grãos da soja, fezse uso da Equação 1 (adaptada de CRUSCIOL \& SORATTO, 2010).

$E f=$ produtividade/dose

em que,

$\mathrm{Ef}=$ eficiência do uso de fertilizante;

Produtividade $=$ grãos de soja em kg/ha; e dose $=$ fertilizante aplicado $(\mathrm{kg} / \mathrm{ha})$.

Nos casos em que houve mais de uma dose na mesma quadrícula, utilizou-se a dose que representou maior área na quadrícula.

$\mathrm{Na}$ análise de dados, efetuou-se: a estatística descritiva (média, valor máximo, valor mínimo, desvio padrão e coeficiente de variação); a 
interpretação dos resultados de análise de solo conforme a classificação proposta por Sousa \& Lobato (2004); e a análise geoestatística por meio do modelo de semivariograma esférico, ajustado ao método Restricted Maximum Likelihood (REML). Em seguida, efetuou-se interpolação por krigagem ordinária e o erro da krigagem ( $\mathrm{R}$ Core Team, 2013).

\section{RESULTADOS E DISCUSSÃO}

Por meio da estatística descritiva, observouse que a maioria dos atributos do solo, nos quatro talhões, apresentou baixa variação. Os menores valores de coeficiente de variação $(\mathrm{CV})$ foram observados no $\mathrm{pH}$ e o maiores no $\mathrm{P}$, e, segundo
Warrick \& Nielsen (1980), a variabilidade dos atributos estudados foi classificada entre baixa e média, exceto para $\mathrm{P}$ dos talhões 1 e 3 , que apresentou alta variabilidade (Tabela 1).

Resultado semelhante foi obtido por Mattioni et al. (2013), em Latossolo cultivado com soja em sistema de plantio direto em Não-Me-Toque, RS, em que o $\mathrm{pH}$ e o $\mathrm{P}$ apresentaram o menor e o maior $\mathrm{CV}$ entre os atributos analisados, respectivamente.

Salienta-se a importância do conhecimento do $\mathrm{pH}$, pois este é considerado como um indicador da fertilidade do solo e pode contribuir para a melhor compreensão do efeito da interferência antrópica no solo (VICENTE \& ARAUJO, 2013).

$\mathrm{O}$ CV da produtividade da soja, conforme Warrick \& Nielsen (1980), foi baixo e variou

Tabela 1. Análise descritiva dos talhões $1,2,3$ e 4 referente ao $\mathrm{pH}\left(\mathrm{CaCl}_{2}\right)$, à produtividade de grãos de soja $\left(\mathrm{kg} / 2,7 \mathrm{~m}^{2}\right)$, argila $(\%)$, matéria orgânica $\left(\mathrm{MO}, \mathrm{g} / \mathrm{dm}^{3}\right)$, potássio $\left(\mathrm{K}, \mathrm{mg} / \mathrm{dm}^{3}\right)$, fósforo $(\mathrm{P}, \mathrm{mg} /$ $\mathrm{dm}^{3}$ ), eficiência de uso do cloreto de $\mathrm{K}(\mathrm{EfKCl})$ e eficiência de uso de superfosfato simples (EfSS)

\begin{tabular}{|c|c|c|c|c|c|c|c|c|}
\hline & $\mathrm{pH}$ & Produtividade & Argila & $\mathrm{MO}$ & $\mathrm{K}$ & $\mathrm{P}$ & $\mathrm{EfKCl}$ & EfSS \\
\hline \multicolumn{9}{|c|}{ Talhão 1} \\
\hline Mínimo & 5,200 & 0,729 & 18,400 & 16,800 & 20,000 & 5,500 & 10,806 & 6,507 \\
\hline Máximo & 5,700 & 1,122 & 59,700 & 35,800 & 70,000 & 49,400 & 40,113 & 20,782 \\
\hline Média & 5,423 & 0,962 & 37,9318 & 26,673 & 37,591 & 24,145 & 23,383 & 13,073 \\
\hline $\mathrm{DP}$ & 0,154 & 0,090 & 16,717 & 6,369 & 12,938 & 16,186 & 10,575 & 5,207 \\
\hline $\mathrm{CV}$ & 2,842 & 9,398 & 44,072 & 23,877 & 34,418 & 67,036 & 45,223 & 39,834 \\
\hline \multicolumn{9}{|c|}{ Talhão 2} \\
\hline Mínimo & 5,300 & 0,999 & 39,000 & 28,700 & 53,000 & 14,000 & 37,008 & 17,648 \\
\hline Máximo & 5,700 & 1,224 & 52,000 & 41,000 & 108,000 & 30,300 & 45,328 & 22,664 \\
\hline Média & 5,496 & 1,133 & 45,263 & 33,900 & 79,917 & 22,017 & 41,943 & 20,788 \\
\hline DP & 0,120 & 0,054 & 4,147 & 3,436 & 12,649 & 4,228 & 2,006 & 1,183 \\
\hline $\mathrm{CV}$ & 2,178 & 4,783 & 9,163 & 10,135 & 15,828 & 19,202 & 4,783 & 5,691 \\
\hline \multicolumn{9}{|c|}{ Talhão 3} \\
\hline Mínimo & 5,200 & 0,765 & 20,100 & 20,600 & 24,00 & 3,300 & 15,353 & 5,240 \\
\hline Máximo & 5,800 & 1,092 & 50,600 & 33,000 & 38,00 & 41,900 & 40,444 & 19,367 \\
\hline Média & 5,508 & 0,945 & 30,818 & 26,087 & 31,564 & 19,423 & 22,619 & 11,474 \\
\hline DP & 0,146 & 0,066 & 9,466 & 3,183 & 3,378 & 13,401 & 7,6135 & 5,151 \\
\hline $\mathrm{CV}$ & 2,647 & 9,939 & 30,715 & 12,201 & 10,702 & 68,994 & 33,660 & 44,891 \\
\hline \multicolumn{9}{|c|}{ Talhão 4} \\
\hline Mínimo & 5,100 & 0,598 & 16,000 & 14,500 & 22,000 & 6,100 & 10,069 & 5,337 \\
\hline Máximo & 5,700 & 1,110 & 34,60 & 30,40 & 53,000 & 51,200 & 37,150 & 20,549 \\
\hline Média & 5,402 & 0,913 & 22,858 & 21,558 & 29,512 & 30,293 & 17,944 & 14,325 \\
\hline DP & 0,165 & 0,103 & 3,996 & 3,492 & 4,527 & 13,357 & 4,742 & 4,209 \\
\hline $\mathrm{CV}$ & 3,063 & 11,245 & 17,480 & 16,199 & 15,340 & 44,093 & 26,428 & 29,380 \\
\hline
\end{tabular}

$\mathrm{DP}=$ desvio padrão; $\mathrm{CV}=$ coeficiente de variação (\%). 
de $4,78 \%$ a $11,25 \%$ (Tabela 1). Diversas pesquisas obtiveram valores de CV próximos aos encontrados neste trabalho (MATTIONI et al. (2013); DALCHIAVON et al. (2017); ACOSTA et al. (2018).

Por meio da avaliação da fertilidade dos talhões estudados, verificou-se que os níveis de $\mathrm{pH}$ variam de adequado a alto, os níveis de $\mathrm{MO}$ e $\mathrm{K}$ de baixo a alto, e P de muito baixo a alto (Tabela 2); essas informações indicam a existência de variabilidade espacial desses atributos do solo, sendo necessário o uso de técnicas geoestatísticas para melhor compreensão do padrão espacial.

Observou-se que a diferença entre as produtividades máxima e mínima de grãos foi de $18,38 \%$ para o talhão $2 ; 29,95 \%$ para o talhão 3 ; $35,03 \%$ para o talhão 1 ; e $46,13 \%$ para o talhão 4 (Tabela 1). Isso pode ser atribuído tanto à heterogeneidade natural dos atributos do solo quanto às práticas de manejo adotadas pelo produtor.

Observou-se dependência espacial para todos os atributos estudados, os quais foram ajustados ao modelo de semivariograma esférico (Tabela 3).

Verificou-se que, nos talhões 1, 3 e 4, os alcances para $\mathrm{P}$ e $\mathrm{MO}$ foram semelhantes, pois variaram de 1035 a $1203 \mathrm{~m}$ e de 820 a $936 \mathrm{~m}$, respectivamente (Tabela 3). Para Carneiro et al. (2016a), os valores de alcance são influenciados pelas práticas agronômicas, principalmente pela aplicação de corretivos e fertilizantes, uma vez que o objetivo é realizar o homogeneização da área de cultivo, sendo que o valor do alcance pode contribuir para o planejamento das futuras malhas amostrais, auxiliando para a otimização do tamanho do grid.

Todos os atributos estudados nos quatro talhões apresentaram variabilidade com padrões espaciais definidos, sendo que os mapas com maiores teores de argila apresentaram área de correspondência com MO, produtividade e eficiência de SS e $\mathrm{KCl}$ (Figuras 3 e 4). Em pesquisa realizada por Richart et al. (2016), também foi verificado que os mapas temáticos foram essenciais para entendimento e avaliações da variabilidade espacial e temporal dos

Tabela 2. Distribuição dos pontos amostrados com seu nível de matéria orgânica (MO), fósforo (P), potássio $(\mathrm{K})$ e potencial hidrogeniônico $(\mathrm{pH})$ em cada talhão avaliado, conforme classificação de Sousa \& Lobato (2004)

\begin{tabular}{ccccccc}
\hline & \multicolumn{5}{c}{ Quantidade de pontos amostrais com seu respectivo nível } \\
\hline Talhão & Atributo & Muito baixo & Baixo & Médio & Adequado & Alto \\
\hline 1 & MO & 0 & 0 & 10 & 12 & 0 \\
1 & $\mathrm{P}$ & 0 & 0 & 5 & 5 & 12 \\
1 & $\mathrm{~K}$ & 0 & 2 & 17 & 3 & 0 \\
1 & $\mathrm{pH}$ & 0 & 0 & 0 & 17 & 5 \\
2 & $\mathrm{MO}$ & 0 & 0 & 5 & 19 & 0 \\
2 & $\mathrm{P}$ & 0 & 0 & 0 & 0 & 24 \\
2 & $\mathrm{~K}$ & 0 & 0 & 0 & 14 & 10 \\
2 & $\mathrm{pH}$ & 0 & 0 & 0 & 15 & 9 \\
3 & $\mathrm{MO}$ & 0 & 0 & 10 & 28 & 1 \\
3 & $\mathrm{P}$ & 5 & 4 & 6 & 5 & 19 \\
3 & $\mathrm{~K}$ & 0 & 1 & 38 & 0 & 0 \\
3 & $\mathrm{pH}$ & 0 & 0 & 0 & 22 & 17 \\
4 & $\mathrm{MO}$ & 0 & 2 & 16 & 24 & 1 \\
4 & $\mathrm{P}$ & 0 & 6 & 3 & 1 & 33 \\
4 & $\mathrm{~K}$ & 0 & 3 & 39 & 1 & 0 \\
4 & $\mathrm{pH}$ & 0 & 0 & 0 & 35 & 8 \\
\hline
\end{tabular}


VARIABILIDADE ESPACIAL DA EFICIÊNCIA DO USO DE POTÁSSIO E FÓSFORO NA CULTURA DA SOJA

Tabela 3. Parâmetros de ajuste do semivariograma para a argila (\%), matéria orgânica $\left(\mathrm{MO}, \mathrm{g} / \mathrm{dm}^{3}\right)$, potássio $\left(\mathrm{K}, \mathrm{mg} / \mathrm{dm}^{3}\right)$, fósforo $\left(\mathrm{P}, \mathrm{mg} / \mathrm{dm}^{3}\right)$, produtividade de grãos de soja $\left(\mathrm{kg} / 2,7 \mathrm{~m}^{2}\right)$, eficiência de uso do cloreto de $\mathrm{K}$ (EfKCl) e eficiência de uso de superfosfato simples (EfSS)

\begin{tabular}{|c|c|c|c|}
\hline & Efeito pepita & Patamar & Alcance \\
\hline \multicolumn{4}{|c|}{ Talhão 1} \\
\hline Argila & 0,375 & 241,000 & 1135,000 \\
\hline $\mathrm{pH}$ & 0,015 & 0,024 & 802,726 \\
\hline MO & 0,000 & 30,340 & 820,144 \\
\hline $\mathrm{K}$ & 31,340 & 171,940 & 665,218 \\
\hline $\mathrm{P}$ & 0,000 & 221,10 & 1202,726 \\
\hline Produtividade & 0,006 & 0,008 & 501,722 \\
\hline EfKCl & 1,982 & 7,140 & 387,466 \\
\hline EfSS & 3,657 & 63,837 & 1213,500 \\
\hline \multicolumn{4}{|c|}{ Talhão 2} \\
\hline Argila & 1,632 & 20,712 & 812,362 \\
\hline $\mathrm{pH}$ & 0,003 & 0,021 & 1065,620 \\
\hline MO & 0,000 & 12,080 & 284,713 \\
\hline $\mathrm{K}$ & 76,110 & 161,870 & 279,942 \\
\hline $\mathrm{P}$ & 15,030 & 17,868 & 199,739 \\
\hline Produtividade & 0,000 & 0,003 & 296,880 \\
\hline EfKCl & 2,923 & 4,279 & 1127,605 \\
\hline EfSS & 0,000 & 23,570 & 227,835 \\
\hline \multicolumn{4}{|c|}{ Talhão 3} \\
\hline Argila & 0,000 & 92,220 & 1557,233 \\
\hline $\mathrm{pH}$ & 0,010 & 0,023 & 724,040 \\
\hline MO & 3,968 & 11,118 & 935,675 \\
\hline $\mathrm{K}$ & 7,189 & 11,683 & 447,701 \\
\hline $\mathrm{P}$ & 15,361 & 164,961 & 1035,454 \\
\hline Produtividade & 0,002 & 0,004 & 337,004 \\
\hline EfKCl & 2,148 & 7,157 & 616,780 \\
\hline EfSS & 1,595 & 31,955 & 1266,935 \\
\hline \multicolumn{4}{|c|}{ Talhão 4} \\
\hline Argila & 0,800 & 24,760 & 1013,014 \\
\hline $\mathrm{pH}$ & 0,014 & 0,029 & 620,239 \\
\hline MO & 3,778 & 16,298 & 900,001 \\
\hline $\mathrm{K}$ & 3,708 & 30,900 & 732,163 \\
\hline $\mathrm{P}$ & 11,26 & 210,861 & 1068,558 \\
\hline Produtividade & 0,000 & 0,010 & 366,968 \\
\hline EfKCl & 2,215 & 8,552 & 1483,927 \\
\hline EfSS & 4,623 & 47,313 & 1617,563 \\
\hline
\end{tabular}

atributos do solo.

A disponibilidade e a variabilidade espacial dos elementos no solo são influenciadas pelas práticas do agricultor, por fatores edafoclimáticos e suas interações. Roger et al. (2014) ressaltaram que é necessária melhor compreensão desses fatores para obtenção do gerenciamento racional dos nutrientes nos sistemas de cultivos agrícolas. 

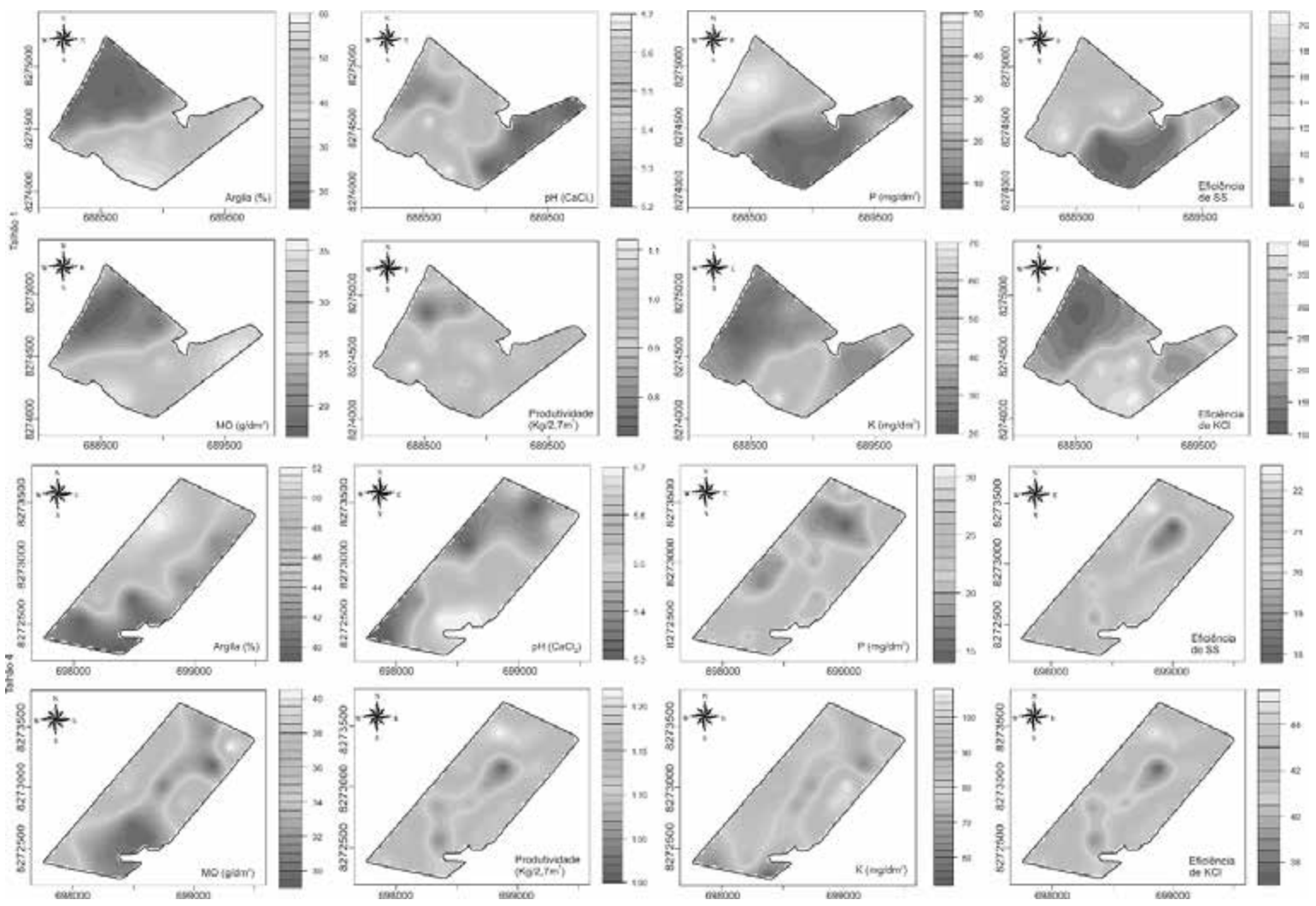

Figura 3. Mapas de krigagem dos talhões 1 e 2 referente aos atributos do solo (argila, $\mathrm{MO}, \mathrm{pH}, \mathrm{P}$ e $\mathrm{K}$ ), à produtividade de grãos de soja, à eficiência de uso de superfosfato simples (SS) e de cloreto de potássio $(\mathrm{KCl})$.

Por meio das informações obtidas pelos mapas de krigagem, observou-se que o talhão 2 foi o que apresentou a menor amplitude para a maioria dos atributos. Em contrapartida, foi observada, no talhão 4 , maior amplitude para a maioria dos atributos (Tabela 3 e Figuras 3 e 4). Como consequência, a produtividade de soja do talhão 4 também apresentou maior variabilidade espacial, comprovando que plantas equilibradas nutricionalmente apresentam maior estabilidade produtiva.

A área de correspondência entre os teores de $\mathrm{K}$ e MO (Figuras 3 e 4) provavelmente ocorreu em função da variação da MO, pois esta disponibiliza nutrientes, age na complexação de elementos tóxicos e de micronutrientes e afeta os agregados e as características biológicas do solo (BAYER \& MIELNICZUK, 2008).

Por meio dos mapas de krigagem, foi possível verificar o potencial de uso de adubação em taxa variável para diminuir a variabilidade espacial dos atributos do solo. Estudo realizado por Carneiro et al. (2016b) verificou que a variabilidade espacial dos atributos químicos de solos também possibilitou recomendar doses de calcário, $\mathrm{P}$ e $\mathrm{K}$ com taxas variadas, proporcionando economia e maior eficiência na aplicação.

Com base nos resultados dos atributos químicos do solo, foi possível constatar também a necessidade de futuras pesquisas, com intuito de obter tabelas de recomendações especialmente para K e P na cultura da soja na região do Cerrado, principalmente para solos com nível médio a alto de $\mathrm{P}$, e considerar o balanço dos nutrientes do sistema de produção, e não apenas de uma cultura específica. Conforme Oliveira Junior et al. (2013), o balanço dos nutrientes nas culturas que compõem o sistema de produção evita o esgotamento gradual de determinado nutriente de forma a atender não apenas as necessidades das culturas, mas também o balanço do sistema de produção.

A resposta da aplicação em taxa variável de SS e $\mathrm{KCl}$ foi satisfatória, pois a produtividade de grãos obtida foi superior à esperada (50 sacas/ha), sendo colhidas em média 56,36, 58,33, 59,38 e 69,94 sacas/ha para os talhões $4,3,1$ e 2, respectivamente 

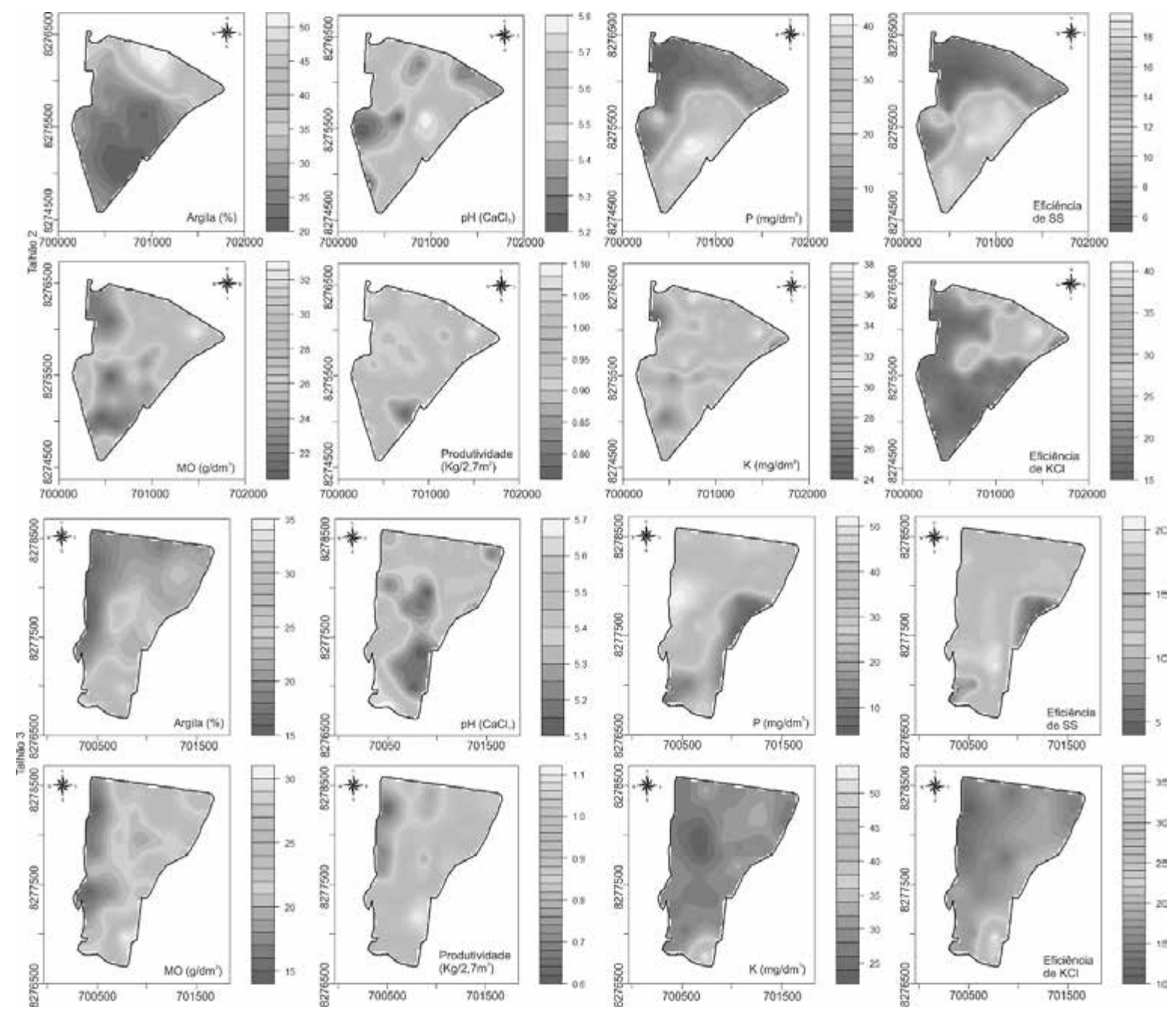

Figura 4. Mapas de krigagem dos talhões 3 e 4 referente aos atributos do solo (argila, MO, pH, $\mathrm{P}$ e K), à produtividade de grãos de soja, à eficiência de uso de superfosfato simples (SS) e de cloreto de potássio $(\mathrm{KCl})$.

(Figuras 3 e 4).

Importante destacar que essas médias foram maiores que a produtividade estadual e nacional; segundo a Conab (2019), estas foram de 50,17 e 48,97 sacas/ha, respectivamente. Salienta-se também que, por esses talhões estarem localizados próximos uns dos outros (Figura 1), dificilmente ocorreu diferença significativa na distribuição das chuvas, haja vista que a estação meteorológica que registrou a distribuição pluviométrica também se localiza próxima aos talhões avaliados.

Observou-se que houve correspondência de áreas principalmente nos talhões 1 e 2 entre a argila e a produtividade, sendo que, nos locais com maior teor de argila, obteve-se maior produtividade (Figuras 3 e 4).

Para Bittar et al. (2013), a proporção relativa de areia, silte e argila modifica o potencial de estoque de nutrientes, carbono e a capacidade de retenção de água nos solos. Conforme Bayer et al. (2006), em solo argiloso há mais estoque de carbono no solo, sugerindo uma maior estabilidade física da MO associada aos minerais argila.

No tocante à eficiência dos fertilizantes, observou-se maior variabilidade para SS e $\mathrm{KCl}$ nos talhões 4 e 1, respectivamente (Figuras 3 e 4), nesses talhões também ocorreu a maior amplitude de $\mathrm{P}$ no solo. No talhão 1 , observou-se o maior gradiente textural e, no talhão 4 , menores teores de MO, haja vista que, em locais com mais argila, normalmente se encontram maiores teores de MO, que, além de disponibilizarem nutrientes, armazenam água e contribuem para a melhoria das condições físicas do solo (Figuras 3 e 4). 
Os resultados permitem inferir que nas áreas dos talhões com os maiores teores de MO ocorreram também a maior eficiência do uso de $\mathrm{KCl}$, devido principalmente à $\mathrm{MO}$ aumentar o potencial de retenção dos nutrientes no solo, pelo aumento da capacidade de troca de cátions (BAYER \& MIELNICZUK, 2008). No entanto, novos estudos são necessários para elucidar melhor essa relação entre a MO e a eficiência de nutrientes.

As informações obtidas por meio dos mapas referentes à eficiência do uso de fertilizantes também contribuem para as tomadas de decisões futuras, além de verificarem, de maneira espacializada, quantos quilogramas de grãos de soja são produzidos por cada $\mathrm{kg}$ de fertilizante aplicado. Crusciol \& Soratto (2010) ressaltaram a importância da eficiência do uso de fertilizantes, devido à elevação dos custos de produção e à necessidade de redução do impacto ambiental da produção agrícola, sendo que há tendência de aumentarem os estudos dessa temática.

A compreensão dos padrões espaciais do $\mathrm{P}$ e do $\mathrm{K}$ no solo é fundamental para o manejo eficiente
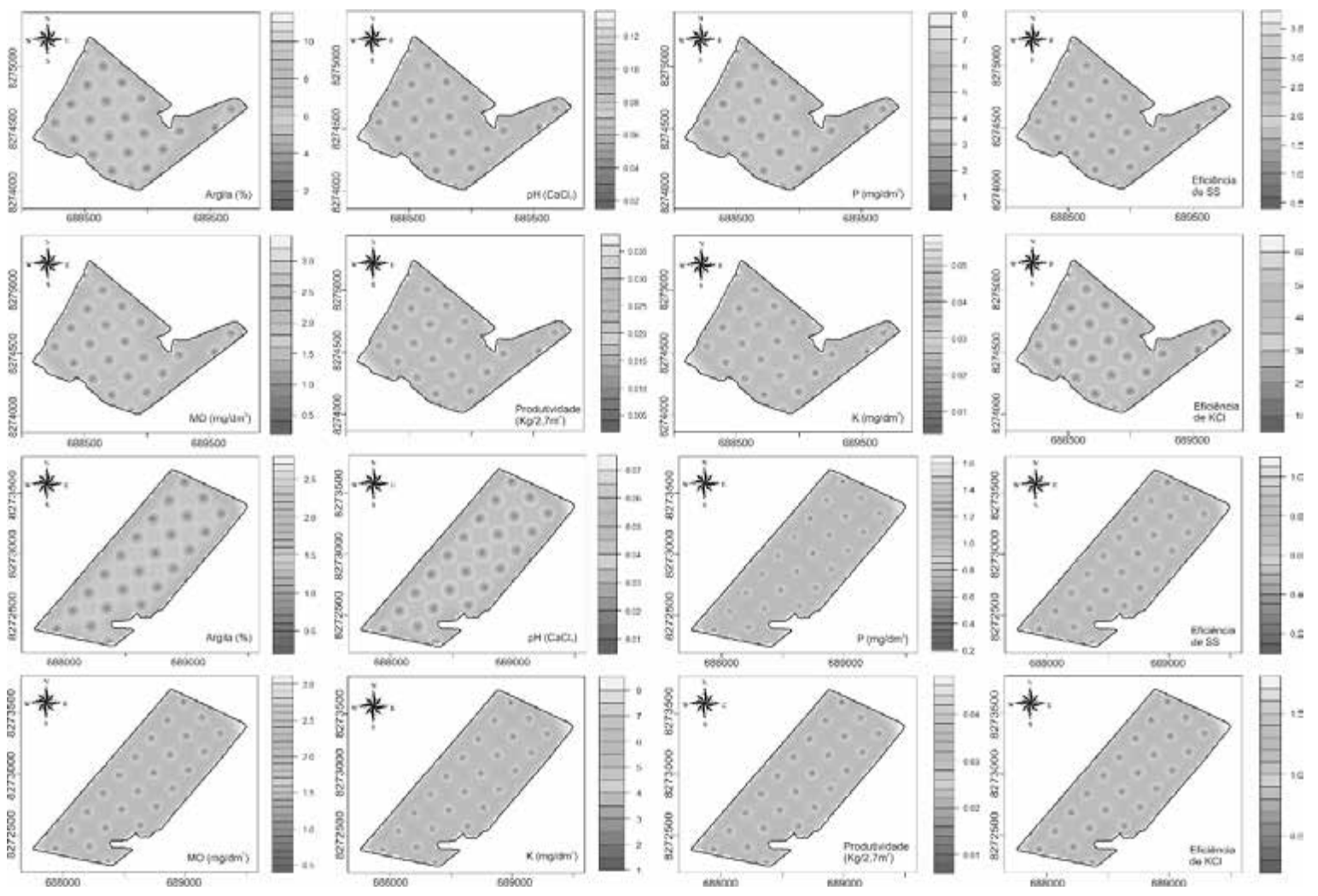

Figura 5. Mapas de erro da krigagem dos talhões 1 e 2 referente aos atributos do solo (argila, MO, pH, $\mathrm{P} \mathrm{e}$ $\mathrm{K}$ ), à produtividade de grãos de soja, à eficiência de uso de superfosfato simples (SS) e de cloreto de potássio $(\mathrm{KCl})$. 

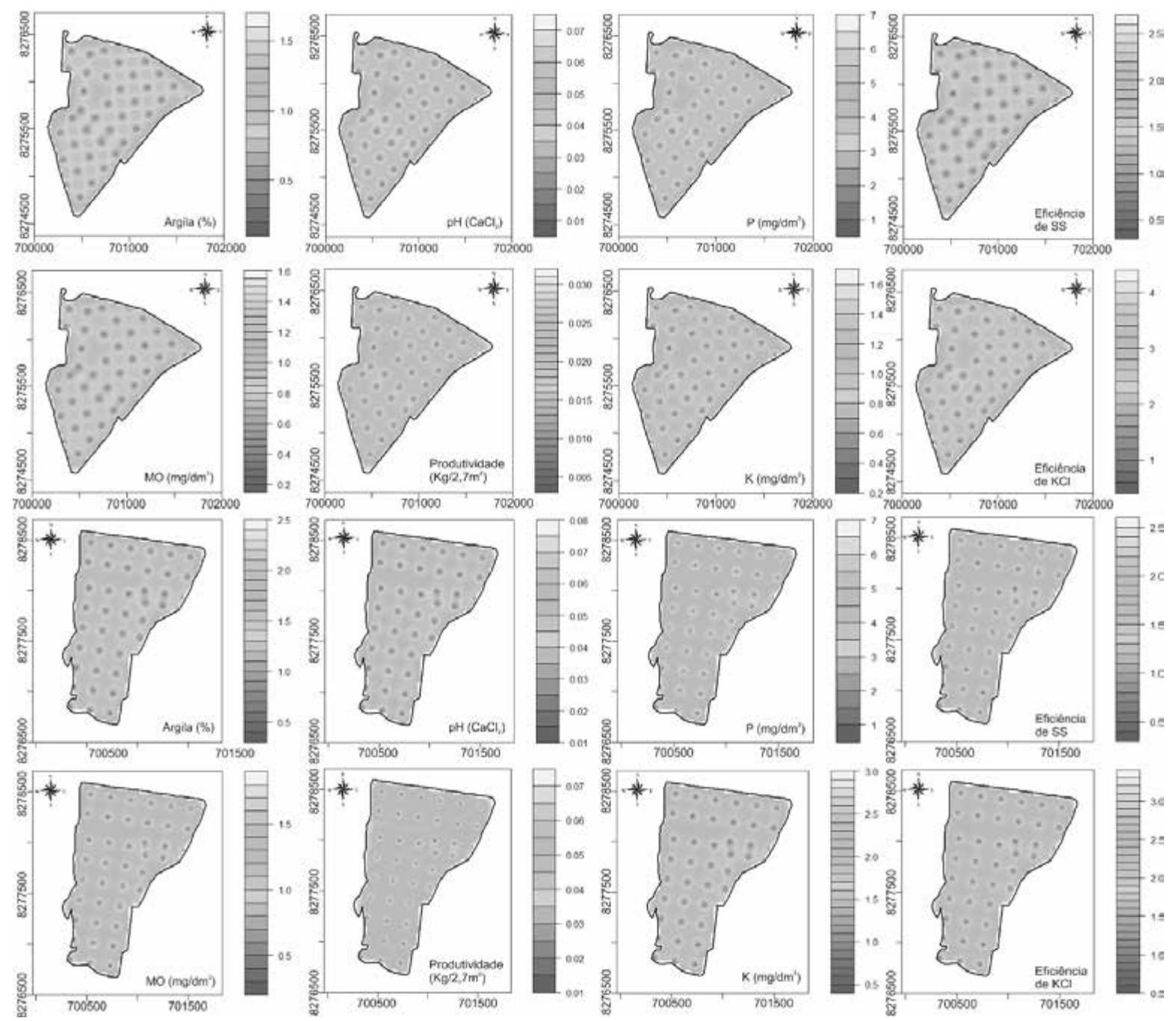

Figura 6. Mapas de erro da krigagem dos talhões 3 e 4 referente aos atributos do solo (argila, MO, pH, $\mathrm{P}$ e K), à produtividade de grãos de soja, à eficiência de uso de superfosfato simples (SS) e de cloreto de potássio $(\mathrm{KCl})$.

\section{CONCLUSÕES}

- Ocorreu dependência espacial para todos os atributos avaliados e foi possível mapear a eficiência de superfosfato simples e cloreto de potássio na cultura da soja.

- O teor de matéria orgânica do solo influenciou positivamente na eficiência de cloreto de potássio.

- Áreas com menor variabilidade espacial dos atributos do solo resultam em maior produtividade de grãos de soja e maior eficiência de superfosfato simples e cloreto de potássio.

\section{AGRADECIMENTOS}

À Coordenação de Aperfeiçoamento de Pessoal de Nível Superior (CAPES), pela bolsa concedida ao primeiro autor.

\section{REFERÊNCIAS BIBLIOGRÁFICAS}

ACOSTA, J.J.B.; CABRERA, M.G.; IBRAS, R.F.; GONZÁLEZ, J.D.; CHAMORRO, S.M.; ESCOBAR, J. Variabilidade espacial da produtividade, perdas na colheita e lucratividade da cultura de soja. Revista Agrogeoambiental, Pouso Alegre, v.10, n.1, p.27-46, 2018.

BAYER, C.; MARTIN-NETO, L.; MIELNICZUK, 
J.; PAVINATO, A.; DIECKOW, J. Carbon sequestration in two Brazilian Cerrado soils under no-till. Soil and Tillage Research, v.86, p.237245, 2006.

BAYER, C., MIELNICZUK, J. Dinâmica e função da matéria orgânica. In: SANTOS, G.A., SILVA, L.S., CANELLAS, L.P., CAMARGO, F.A.O. (Eds.). Fundamentos da matéria orgânica do solo: ecossistemas tropicais \& subtropicais. 2ed. revisada e atualizada, Porto Alegre: Metropole, p.7-18, 2008.

BITTAR, I.M.B.; FERREIRA, A.S.; CORRÊA, G.F. Influência da textura do solo na atividade microbiana, decomposição e mineralização do carbono de serapilheira de sítios do bioma cerrado sob condições de incubação. Bioscience Journal, Uberlândia, v.29, n.6, p.1952-1960, 2013.

BOTTEGA, E.L.; PINTO, F.A.C.; QUEIROZ, D.M.; SANTOS, N.T.; SOUZA, C.M.A. Variabilidade espacial e temporal da produtividade de soja no cerrado brasileiro. Revista Agrarian, Dourados, v.6, n.20, p.167-177. 2013.

CARNEIRO, J.S.S.; FARIA, A.J.G.; FIDELIS, R.R.; SILVA NETO, S.P.; SANTOS, A.C.; SILVA, R.R. Diagnóstico da variabilidade espacial e manejo da fertilidade do solo no cerrado. Revista Scientia Agraria, Curitiba, v.17, n.3, p.38-49, 2016a.

CARNEIRO, J.S.S.; SANTOS, A.C.M.; FIDELIS, R.R.; SILVA NETO, S.P.; SANTOS, A.C.; SILVA, R.R. Diagnóstico e manejo da variabilidade espacial da fertilidade do solo no cerrado do Piaú. Revista de Ciências Agroambientais, Alta Floresta, v.14, n.2, p.10-21, 2016b.

CARVALHO, P.S.M.; SILVA, S.A.; PAIVA, A.Q.; SODRÉ, G.A.; LIMA, J.S.S. Revista Engenharia na Agricultura; Viçosa, v.26, n.2, p.178-189, 2018.

CONAB. Séries Históricas: Soja. Disponível em: http://www.conab.gov. $\mathrm{br} / \mathrm{conteudos} . \mathrm{ph} \mathrm{p} ? \mathrm{a}=1252 \& \mathrm{t}=2 \& \mathrm{Pagina}$ objcmsconteudos=3\#A_objcmsconteudos. Acesso em: 16 abr2019.

CRUSCIOL, C.A.C.; SORATTO, R.P. Sistema de produção e eficiência agronômica de fertilizantes. In: PROCHNOW, L.I.; CASARIN, V.; STIPP, S.R. (Eds.). Boas práticas para uso eficiente de fertilizantes: contexto mundial e práticas de suporte. Piracicaba: International Plant Nutrition Institute, v.1, p.229-279, 2010.

DALCHIAVON, F.C.; RODRIGUES, A.R.; LIMA, E.S. de; LOVERA, L.H.; MONTANARI, R. Variabilidade espacial de atributos químicos do solo cultivado com soja sob plantio direto. Revista de Ciências Agroveterinárias, Lages, v.16, n.2, p.144-154, 2017.

EMBRAPA SOJA. Tecnologias de produção de soja - região Central do Brasil 2012 e 2013. Londrina: Embrapa Soja, 2011. 261p. (Sistemas de Produção / Embrapa Soja, ISSN 2176- 2902; n.15).

MATTIONI, N.M.; SCHUCH, L.O.B.; VILLELA, F.A. Variabilidade espacial e efeito de atributos químicos de um Latossolo na população de plantas e produtividade da cultura da soja. Revista da FZVA, Uruguaiana, v.19, n.1, p.20-32, 2013.

MELO, V.F.; ALLEONI, L.R.F. Química e Mineralogia do solo: Parte I- Conceitos Básicos. Sociedade Brasileira de Ciência do Solo. 695p. 2009.

MONTEBELLER, C.; CEDDIAS, M.B.; CARVALHO, D.F.; VIEIRA, S.R.; FRANCO, E.L.M. Variabilidade espacial do potencial erosivo das chuvas no Estado do Rio de Janeiro. Engenharia Agrícola, Jaboticabal, v.27, p.426435, 2007.

OLIVEIRA JUNIOR, A.; CASTRO, C.; OLIVEIRA, F.A.; JORDÃO, L.T. Adubação potássica na soja: cuidados no balanço de nutrientes. Informações Agronômicas, Piracicaba: International Plant Nutrition Institute, n.143, p.1-10. 2013. 
$\mathrm{R}$ Core Team. R: language and environment for statistical computing. R Foundation for Statistical Computing, Viena, Austria, 2013.

REETZ JR. H.F. Precision farming as an instrument for fertilizer Best management practices. In: PROCHNOW, L.I., CASARIN, V.; STIPP, S.R. (Eds.). Boas práticas para uso eficiente de fertilizantes: culturas. Piracicaba: International Plant Nutrition Institute, v.3, p.199-214, 2010.

ROGER, A.; LIBOHOVA, Z.; ROSSIER, N.; JOOST, S.; MALTAS, A.; FROSSARD, E.; SINAJ, S. Spatial variability of soil phosphorus in the Fribourg canton, Switzerland. Geoderma, v.217-218, p.26-36, 2014.

RICHART, A.; PICCIN, A.L.; KONOPATZKI, M.R.S.; KAEFER, K.A.C.; MORATELLI, G.; KAEFER, J.E.; ECCO, M. Análise espaço-temporal de atributos químicos do solo influenciados pela aplicação de calcário de cloreto de potássio em taxa variável. Scientia Agraria Paranaensis, Marechal Cândido Rondon, v.15, n.4, p.391-400, 2016.

SANTOS, H.G. DOS; JACOMINE, P.K.T.;
ANJOS, L.H.C. DOS; OLIVEIRA, V.A. de; LUMBRERAS, J.F.; COELHO, M.R.; ALMEIDA, J.A. de; CUNHA, T.J.F.; OLIVEIRA, J.B. de (Ed.). Sistema brasileiro de classificação de solos. 3 . ed. revisada e ampliada. Brasília: Embrapa, 2013. 353p.i1.

SOUSA, D.M.G.; LOBATO, E. Cerrado: correção do solo e adubação. 2ed. Brasília: Embrapa Cerrados, 2004. 416p.

VICENTE, G.C.P.; ARAUJO, F.F. Uso de indicadores microbiológicos e de fertilidade do solo em áreas de pastagens. Semina: Ciências Agrárias, v.34, n.1, p.137-146, 2013.

ZONTA, J.H.; BRANDÃO, Z.N.; MEDEIROS, J.C.; SANA, R.S.; SOFITTI, V. Variabilidade espacial da fertilidade do solo em área cultivada com algodoeiro no Cerrado do Brasil. Revista Brasileira de Engenharia Agrícola e Ambiental, Campina Grande, v.18, n.6, p.595-602, 2014. WARRICK, A.W.; NIELSEN, D.R. Spatial variability of same physical properties of the soil. In: Hillel, D. ed. Applications of soil physics, New York: Academic Press, p.319-344, 1980. 